\title{
A VIVÊNCIA DA ENFERMEIRA NO PROCESSO DE MORTE E MORRER DOS PACIENTES ONCOLÓGICOS
}

\author{
Daniele Martins de Sousa ${ }^{1}$,Erida de Oliveira Soares², Kamyla Maria de Souza Costa ${ }^{3}$, Alexandra Lílian de \\ Carvalho Pacífico ${ }^{4}$ Adriana da Cunha Menezes Parente 5
}

\footnotetext{
${ }^{1}$ Enfermeira do Hospital Mariano Castelo Branco. Piauí, Brasil. E-mail: anielemartinss@hotmail.com

${ }^{2}$ Especialista em Saúde da Família. Enfermeira dos Hospitais Prontomed e Mariano Castelo Branco. Piauí, Brasil. E-mail: eridasoares@hotmail.com

${ }^{3}$ Enfermeira. Professora do Centro Educacional São Camilo. Piauí, Brasil. E-mail: kamylamaria@hotmail.com

${ }^{4}$ Enfermeira. Professora do Centro Educacional São Camilo. Piauí, Brasil. E-mail: voltei041@hotmail.com

${ }^{5}$ Mestre em Enfermagem Psiquiátrica. Professora da Faculdade de Ciências Humanas e Tecnológicas do Piauí. Piauí, Brasil. E-mail: aparente@novafapi.com.br
}

\begin{abstract}
RESUMO: Trata-se de um estudo qualitativo, exploratório e descritivo que objetivou descrever e analisar a vivência do enfermeiro no processo de morte e morrer dos pacientes oncológicos. A coleta de dados deu-se através de entrevistas semi-estruturadas realizadas no período de setembro a outubro de 2007, com 10 enfermeiras. Estas entrevistas foram analisadas tendo como pressupostos norteadores a análise de conteúdo, modalidade temática. Nos resultados e discussão, os depoimentos obtidos foram categorizados como: o significado da morte para a enfermeira, o envolvimento no processo de morte e morrer dos pacientes oncológicos e o preparo emocional das enfermeiras diante do processo de morte e morrer. Estes profissionais demonstram em seus discursos uma grande ansiedade em lidar com a morte, procurando negá-la, já que esta se constitui em um fenômeno doloroso e de difícil aceitação.
\end{abstract}

DESCRITORES: Oncologia. Enfermagem oncológica. Morte. Tanatologia.

\section{THE NURSE'S EXPERIENCE WITH THE DEATH AND DYING PROCESS AMONG ONCOLOGY PATIENTS}

\begin{abstract}
The objective of this qualitative, exploratory, and descriptive study is to describe and to analyze the nurse's lived experiences concerning the death and dying process among oncology patients. The data was collected through semi-structured interviews carried out with ten nurses from September to October of 2007. This data was analyzed based on the content analysis and thematic modality. In the results and discussion, the depositions obtained were categorized as: the meaning of death for the nurse; involvement in the death and dying process among oncology patients; and emotional preparation for nurses to face this process. These professionals demonstrate in their speeches a great anxiety in dealing with death, seeking to deny it since death constitutes a painful and difficult to accept phenomenon.
\end{abstract}

DESCRIPTORS: Medical oncology. Oncologic nursing. Death. Thanatology.

\section{LA VIVENCIA DEL ENFERMERO EN EL PROCESO DE LA MUERTE Y EL MORIR DE LOS PACIENTES ONCOLÓGICOS}

\begin{abstract}
RESUMEN: Se trata de un estudio cualitativo, exploratorio y descriptivo cuyo objetivo es describir y analizar la vivencia del enfermero en el proceso de la muerte y del morir de los pacientes oncológicos. La recolección de los datos se hizo a través de entrevistas parcialmente estructuradas, realizadas en los meses de septiembre y octubre del 2007, con diez enfermeras. Las entrevistas fueron analizadas teniendo como presupuestos orientadores el análisis de contenido y la modalidad temática. En los resultados y en la discusión, las declaraciones obtenidas fueron categorizadas como: el significado de la muerte para el enfermero, la participación en el proceso de muerte y del morir de los pacientes oncológicos, y la preparación emocional de los enfermeros para enfrentar ese proceso. Estos profesionales demuestran en sus discursos una gran ansiedad para hacer frente a la muerte procurando negarla, ya que ésta se convierte en un fenómeno doloroso y de difícil aceptación.
\end{abstract}

DESCRIPTORES: Oncología médica. Enfermería oncológica. Muerte. Tanatología. 


\section{INTRODUÇÃO}

Nos dias atuais, apesar do progresso da $\mathrm{Me}-$ dicina em relação aos procedimentos realizados para o tratamento das doenças terminais, o câncer ainda é uma patologia que se reveste de estigmas, estando quase sempre associada a uma sentença de morte, podendo ocorrer, de forma inesperada, em algum momento da vida de uma pessoa que dificilmente encontra-se preparada para receber um diagnóstico que venha a interferir em seus hábitos, costumes, integridade física e ciclo biológico.

Essa doença tem sido vista como um processo irreversível e cheio de significados para o paciente e equipe de saúde, que se estabelecem a partir de vivências sócio-culturais, mitos, medos e incertezas formados desde o momento em que se dá a possibilidade, mesmo que remota, de seu diagnóstico. Por ser uma patologia que se reveste de incógnitas, causa previsões futuras as quais se constituem de uma infinidade de sofrimentos, idas e vindas aos hospitais, do desamparo que irão produzir a seus familiares, paralisação de suas atividades profissionais, enfim, de toda sorte de angústia, desespero e extremo negativismo, predominando o medo e o descontrole emocional desencadeados pelo fato do paciente ter intenso impacto e sensação de morte iminente. ${ }^{1-2}$

Assim, a morte, apesar de inevitável em algum momento da vida do ser humano, não é uma questão simples de ser discutida, uma vez que, em nossa cultura, muitas vezes é representada pelo pavor e pela não aceitação. Tanto para os pacientes oncológicos, quanto para aqueles que não têm a doença, o estigma da morte relacionada ao câncer encontra-se arraigado na mentalidade das pessoas, o que gera um pavor intenso, pois o homem não tende a encarar abertamente o seu fim de vida no plano terrestre, o que só eventualmente vem ocorrer quando sua vida encontra-se ameaçada por uma certa doença, existindo um receio intenso em lidar com a morte que está intimamente ligado ao instinto de sobrevivência humana. ${ }^{3}$

Nos últimos séculos, a morte ainda tem sido vista como um tabu, às vezes como tema interditado, podendo representar um sinônimo de fracasso profissional na sociedade ocidental, onde as pessoas procuram negá-la como se existencialmente a vida fosse dela desintegrada. ${ }^{4-5}$

A negação da morte é perceptível em todos os setores da sociedade, até mesmo entre os profissionais da saúde, que, na linguagem do dia-a-dia, comumente referem-se à mesma como óbito. ${ }^{6-7}$
Por herança cultural ou formação pessoal, cada ser humano carrega dentro de si uma representação individual da morte. A esta são atribuídas influências do convívio social, meios de comunicação e particularidades de cada indivíduo que contribuem para sua mistificação.

E é neste cenário de diversidade com relação à morte que se encontram os profissionais de enfermagem, vivendo em constante desafio, uma vez que diariamente permanecem em conflito, lutando pela vida e contra a morte, tomando para si a responsabilidade de salvar, curar ou aliviar, procurando sempre preservar a vida, já que a morte, na maioria das vezes, é vista por estes profissionais como um fracasso, sendo, desta forma, duramente combatida. ${ }^{8}$

A enfermeira é quem geralmente está próximo nos momentos difíceis, é quem o paciente e a família buscam quando necessitam de esclarecimentos, ou de cuidados imediatos. Assim este profissional tem que lidar com o sofrimento, com a angústia e com os temores que podem surgir em diversas situações que envolvem esse cuidar. ${ }^{9}$

A prestação destes cuidados, para ser considerada de forma efetiva, requer do enfermeiro não só o conhecimento da patologia em si, mas, além disso, a habilidade em lidar com os sentimentos dos outros e com as próprias emoções frente ao doente com ou sem possibilidade de cura. É preciso olhar para as necessidades não ditas, perceber o imperceptível, compreender o que se oculta atrás das palavras, entender os processos da morte e do morrer para que se torne capaz de auxiliar os pacientes na sua finitude, pois o conhecimento insuficiente destes aspectos poderá levar a um distanciamento do paciente como uma forma de proteção por não saber enfrentar tal situação e uma falha na prestação do cuidado singular/integral tão almejado pela Enfermagem. ${ }^{10}$

Estudos recentes trazem que o sentimento de medo e insegurança, em muitas ocasiões, é referenciado como uma lacuna no ensino de graduação, que muitas vezes não prepara o profissional para a dura rotina dos hospitais, local em que se convive constantemente com o sofrimento alheio, fazendo com que o enfermeiro deixe de assumir uma postura terapêutica nestas situações, sendo raro encontrar nos hospitais enfermeiros capazes de dialogar com a família e o moribundo, assistindo-os em suas necessidades psicológicas nos momentos que antecedem à morte. ${ }^{11-13}$

Assim, considera-se este estudo significativo para compreender a vivência deste profissional no 
processo de morte e morrer, tendo em vista que, durante a graduação de enfermagem, a abordagem do tema morte pode limitar-se muitas vezes ao caráter técnico, com valorização da manutenção da vida, podendo gerar assim algumas incertezas quanto ao preparo dos futuros enfermeiros em lidar com o processo de terminalidade de seus pacientes.

Deste modo, visando um contínuo aperfeiçoamento para uma melhor qualidade na assistência prestada no processo de morte e morrer dos pacientes oncológicos, este estudo teve como objetivos descrever e analisar a vivência do enfermeiro no processo de morte e morrer dos pacientes oncológicos.

\section{METODOLOGIA}

Essa pesquisa foi desenvolvida dentro dos pressupostos do método qualitativo descritivo exploratório, tendo em vista a natureza do objeto e dos objetivos propostos neste estudo. ${ }^{14}$

O estudo foi realizado em um Hospital Filantrópico de Teresina-PI, que se destina ao atendimento de pacientes oncológicos. Participaram 10 enfermeiras que vivenciaram o processo de morte e morrer dos pacientes oncológicos, com idades de 23 a 37 anos, tempo de graduação entre seis meses e 12 anos, todas pertencentes à religião católica e, apenas uma com pós-graduação em oncologia clínica.

A coleta de dados deu-se após a autorização do Hospital e aprovação do Comitê de Ética em Pesquisa da Faculdade de Saúde Ciências Humanas e Tecnológicas do Piauí - NOVAFAPI em agosto de 2007, sob o processo CAAE $\mathrm{N}^{\circ}$ 0093.0.043.000-07. Todos os sujeitos desta pesquisa receberam um convite individual para a participação voluntária no estudo, sendo que no início de cada entrevista foi lido e assinado o Termo de Consentimento Livre e Esclarecido.

A técnica utilizada para coleta de dados foi um roteiro de entrevista semi-estruturada composto por duas partes: a primeira constituída com dados de caracterização das participantes, e a segunda com questões que possibilitaram maior flexibilidade, profundidade, reiteração e reflexão, combinando perguntas fechadas e abertas, o que permitiu às entrevistadas a possibilidade de discorrer sobre o tema proposto sem a submissão de condições pré-fixadas pelo entrevistador. ${ }^{15}$ Para o registro das entrevistas, utilizou-se gravador.

Os dados coletados foram submetidos à análise de conteúdo, modalidade temática, ${ }^{15}$ onde os discursos apreendidos foram categorizados em: o significado da morte para o enfermeiro, o envolvimento no processo de morte e morrer dos pacientes oncológicos e o preparo emocional dos enfermeiros diante do processo de morte e morrer.

\section{RESULTADOS E DISCUSSÃO}

\section{O significado da morte para a enfermeira}

A morte de um paciente causa grande impacto na identidade pessoal e profissional de toda equipe envolvida no seu cuidado, em especial para a enfermeira. O modo como a enfermeira compreende o conceito de morte, bem como a forma que relaciona este conceito com o seu próprio existir e as suas vivências pessoais de perdas anteriores dentro e fora do âmbito profissional são aspectos que influirão na sua atuação diante da morte. ${ }^{9}$

Assim, o significado de morte apareceu em todos os discursos das entrevistadas, e embora todas tenham reconhecido que a mesma faz parte da existência humana, vários significados foram atribuídos a ela, e alguns dos depoimentos expressaram o sentimento de negação. Esses sentimentos contribuem para que a enfermeira recuse-se a falar sobre a morte e muito menos ouvir algo a seu respeito. ${ }^{16}$

Para mim a morte é o que todo mundo sabe que vai passar um dia, mas ninguém quer (D9).

Eu confesso que procuro evitar pensar na morte, apesar de sempre conviver com isso por conta da minha profissão [...] na verdade é que ninguém está preparado para morrer (D10).

É complicado falar da morte, pois a morte é algo que todos sabemos que um dia irá acontecer, mas nunca queremos que ela chegue [...] algo que muitas vezes você já sabe que não vai escapar, mas não quero aceitar, não me conformo e principalmente se for uma pessoa jovem que tem toda a vida pela frente [...] (D1).

Entende-se que no que se refere à morte, apesar da convivência da enfermeira em seu diaa-dia com essa possibilidade, sempre são compartilhados os mesmos conceitos e sentimentos manifestados pelas pessoas em geral, que podem ser os mais variados, até porque o outro é o seu referencial externo e através desta relação pode ocorrer identificação. ${ }^{17}$ Nos discursos apresentados, é freqüente a caracterização da morte como perda, dor, passagem para vida eterna e o fim.

A morte anda junto com a saudade, com a perda de alguém, a falta eterna que você vai sentir daquela pessoa que você ama (D9). 
A morte para mim é uma passagem, uma continuação da vida em outro plano. Esse outro plano é onde acontece o restante da vida, ou seja, estamos em um plano de uma vida na terra e durante essa transição, essa passagem, iremos dar continuidade de vida em outro lugar, o céu, por exemplo (D8).

Algo inexplicável, o fim de uma longa caminhada, especialmente para os pacientes oncológicos que, depois de tanto sofrimento, depois de tanto lutar contra a doença, chegam a esse fim (D3).

Esses achados se identificaram com o que foi proposto em outro estudo, ${ }^{18}$ onde os autores afirmam que os profissionais de saúde, incluindo as enfermeiras, apresentam sentimentos de perda, dor e tristeza ao dar significado à palavra morte e que este significado é determinado tendo em vista o contexto sócio-cultural em que está inserido este profissional, ou seja por todas as situações vividas em seu cotidiano, dentro e fora do contexto hospitalar, sobretudo o que tange à religião. Quanto a isto, alguns profissionais de enfermagem tendem a associar à morte o significado de transcendência, com a tendência de vê-la como uma passagem e não um fim.

É tipo assim, uma passagem, uma passagem de vida. Você sai do material e vai para o espiritual. É assim, eu acho que não acaba. Eu sou católica, tenho que acreditar na ressurreição (D2).

Então, para mim, a morte está muito relacionada com a religião, de acreditar que é uma passagem. Estamos vivendo nessa vida e a morte é uma passagem para outra vida, para dar continuidade em outra vida (D7).

Torna-se evidente que a vivência desses profissionais diante da morte de seus pacientes é um fato difícil e delicado de se conduzir, gerando a não aceitação pela consciência do profissional, mas emergindo de sua inconsciência e evidenciando-se em seus atos. A problemática experimentada pelos enfermeiros no relacionamento com os doentes em fase terminal deve-se, em boa parte dos casos, à dificuldade de lidar com seus próprios temores da morte, sobressaindo, então, as defesas. ${ }^{19}$

\section{O envolvimento no processo de morte e morrer dos pacientes oncológicos}

A enfermeira é a profissional que se mantém sempre presente ao lado do paciente, prestandolhe cuidados diretos, o que pode desencadear um envolvimento afetivo. Este é concebido como sendo uma forma de comportamento em que uma pessoa mantém a proximidade com outra, que é diferente e preferida. É considerado como uma base de segurança e quando por algum motivo é interrompido, como o que acontece com a morte, gera sofrimento e sentimento de perda, ou seja, provoca o luto que é uma resposta esperada frente à separação. ${ }^{20}$

Ao assistir o paciente oncológico em seu processo de morte e morrer, a enfermeira vivencia situações permeadas por sofrimento, angústia, medo, dor e revolta por parte do paciente e de seus familiares, e como um ser humano dotado de emoções e sentimentos manifesta em alguns momentos estas mesmas reações diante deste processo. ${ }^{21}$

[...] quando o paciente evolui bem, você chega a pensar que logo logo ele terá alta, e quando menos espera, agrava e chega a falecer, aí sofro muito. Poxa! Ele ia tão bem, já ia até ter alta [...] (D3).

No meu caso, que eu trabalho com crianças... aí vai gerar o que? Vai gerar revolta... principalmente nos pais, mães, parentes e irmãos (D6).

Para mim éo processo mais sofrido, são pacientes que vão acabando, sabe, vão complicando [...] (D4).

Quanto a isso, há profissionais de saúde, sobretudo as enfermeiras, que chegam a afirmar que podem existir pacientes com os quais se estabelece uma relação diferenciada e singular, e ao vivenciarem seu processo de morte, emergem sentimentos de tristeza e sensação de vazio, pois a preservação e o prolongamento da vida são os seus objetivos, por conseguinte, podem sentir-se incapazes ou frustrados quando não obtêm êxitos em suas tentativas. ${ }^{18-19}$

[...] então, quando você se apega com uma pessoa, com esses pacientes e eles chegam a morrer, você sente [...] minha tarde naquele dia acabou porque me apeguei muito a ela [...] quando cheguei em casa, chorei tanto, tanto que nem lembro a última vez que tinha chorado tanto assim (D10).

Nem me fale, é horrível, dolorido demais, a familia chorando, o paciente agonizando [...] é doloroso demais [...] (D1).

[...] tem pacientes que fico tão amiga dele e da família que quando ele morre, fico o tempo todo com ele na memória, fico trabalhando, mas com o pensamento nele, meu Deus, fulano morreu! (D1).

É assim, um sofrimento porque a gente termina gostando, se apega [...] termina conhecendo a mãe, o pai, o filho, termina conhecendo a família toda, porque eles estão mais aqui do que em casa [...] então para mim, a morte mais difícil, mais sofrida é a do paciente oncológico (D9). 
A morte nem sempre atinge a equipe de saúde de forma semelhante, sendo que o nível da perda é determinado pela condição em que se apresenta o paciente, e, sobretudo, pelo grau de envolvimento, onde esse evento se constitui em um término de um relacionamento afetivo estabelecido, o rompimento de um vínculo. ${ }^{22}$

Podemos perceber, que o envolvimento no processo de morte e morrer está intimamente relacionado com o tempo de permanência do paciente durante a internação, o que contribui para que o sofrimento da enfermeira torne-se mais intenso com a morte dos pacientes que permanecem mais tempo hospitalizados, com os quais conseqüentemente forma-se um maior vínculo.

Além disso, o sentimento de perda em relação ao paciente torna-se mais profundo quando se trata de uma criança, onde há um envolvimento maior com a enfermeira, talvez pela própria singularidade da infância ou por se considerar esta perda como uma morte inoportuna. Este fato foi comprovado durante os depoimentos, onde se verificou uma maior ênfase ao sofrimento enfrentado pelos profissionais que atuam na unidade de oncologia pediátrica.

Então, é difícil, no meu caso assim, são crianças, sofrem muito. E a gente se apega, não é? Tem toda uma relação de carinho, de confiança na gente, de esperança que elas depositam também nelas, de que vão ficar curadas, de que a gente vai vê-las crescer, estudar, e às vezes, de repente, a gente é surpreendida tanto quanto a família por uma piora clínica da criança e aí a gente tem em conseqüência a morte. E assim é muito difícil [...] (D6).

Porque criança é sempre mais chocante, não é? Poxa! A gente pensa... tem toda vida pela frente. Eu sou muito envolvida com elas, sou muito envolvida com minhas crianças. Então, para mim, que trabalho diretamente com elas é mais doloroso (D2).

A maior angústia manifestada por parte das enfermeiras diante da morte da criança acontece quase sempre porque a criança está no início de sua vida, por interromper seu ciclo vital ainda na infância, não participando das mudanças que envolvem o crescer e o desenvolver, não passando pela fase de trabalho, casamento, filhos, e não poder aproveitar uma boa velhice. Enfim, não desfrutar de uma vida cheia de sonhos e esperanças. ${ }^{23}$

Porém, em contrapartida, por estar intimamente envolvido com o paciente a quem presta cuidados, a morte, algumas vezes, pode ser vista como alívio para o sofrimento, uma vez que por mais que a enfermeira sofra com a morte do seu paciente, ele também não se sente à vontade ao visualizar o sofrimento do paciente oncológico fora de possibilidades terapêuticas. ${ }^{24}$

E essa questão do alívio que eu quis dizer é que às vezes a gente tem pacientes que vêm três... quatro meses de internação, sofrendo... às vezes não reage ao tratamento, vai tendo várias complicações. Complicação em cima de complicação [...] e às vezes a gente até se conforma [...] (D6).

[...] mas na minha área de atuação, a condição terminal tem sentido positivo, quando todo aquele desconforto físico, emocional e espiritual tem um fim, quando a pessoa cuidada morre sem dor, morre acompanhada daqueles que amam, quando deu um sentido a sua existência e a de seus familiares (D5).

[...] às vezes, num estágio mais avançado, quando o paciente morre, temos aquele sentimento: Poxa descansou! Porque quem trabalha de perto sabe o quanto que é sofrido (D2).

\section{O preparo emocional dos enfermeiros diante do processo de morte e morrer}

O câncer é uma patologia cheia de estigmas, que "ainda é percebida como uma doença que leva inexoravelmente à morte e acompanhada de dor e sofrimento intoleráveis" ${ }^{2: 267}$ Neste estudo, a vivência da enfermeira no processo de morte e morrer destes pacientes oncológicos, foi compreendida como um processo difícil e sem muitas expectativas por parte das enfermeiras entrevistadas, o que gera, nestas profissionais, uma angústia que, conseqüentemente, proporciona uma fuga de seu verdadeiro papel de profissional responsável pelo cuidar.

Ao tomar consciência de sua fundamental importância no desenvolvimento de atividades que proporcionem conforto e bem estar físico e mental à pacientes, fora de possibilidades terapêuticas, as enfermeiras encontram-se diante do paradoxo existente entre o cuidar de forma humanizada e suas convicções sócio-culturais que envolvem o medo, a angústia e as dificuldades diante do prognóstico do paciente oncológico.

A morte faz parte do decurso normal da vida, mas as enfermeiras geralmente não estão preparadas emocionalmente para enfrentar a morte e nem lidar com seus próprios sentimentos, como também sentem dificuldades em assistir os pacientes que irrevogavelmente, de forma lenta ou brusca, evoluirão para morte. ${ }^{16,19,25}$

[...] ninguém está preparado, é muito difícil até como profissional, por mais que eu vivencie muito, na hora não sei o que falar, nem o que fazer [...] (D7). 
[...] realmente foi aquele choque, porque eu não estava preparada emocionalmente para ver aquele paciente morrer ali na minha frente, não estava preparada [...] (D4).

[...] Apesar de alguns anos trabalhando com oncologia, eu ainda não tenho um emocional suficientemente preparado para suportar os processos de morte e morrer [...] somos preparados para o cuidar e evitar doenças, promover a saúde e assegurar a continuidade da vida, mas não somos preparados para o cuidar no processo de vida para a morte [...] (D5).

O profissional destinado a cuidar de pacientes em fase terminal deve ser preparado para enfrentar situações de extremo sofrimento e de morte, pois a morte reflete um limite da capacidade do profissional. ${ }^{13,19}$ Porém, apesar das enfermeiras conviverem diariamente com situações de sofrimento diante do processo de morte de seus pacientes, percebe-se que ainda emergem reações diversas destas enfermeiras frente a esta vivência, já que o estresse, a ansiedade e a fuga como mecanismos de defesa durante a assistência profissional se mostraram evidentes neste processo.

[...] tem uns pacientes que nos apegamos tanto que é muito difícil de agüentar... choramos, lamentamos, nos sentimos potencialmente incapazes... somos preparados para o cuidar e evitar doenças, a promover a saúde, a assegurar a continuidade da vida..., mas não somos preparados para o cuidar no processo de vida para a morte [...] (D5).

[...] ninguém está preparado, por mais que seja um processo crônico de doença, ninguém está preparado, é muito difícil e assim, e quando tem realmente a morte até como profissional, por mais que eu vivencie muito, na hora não sei o que falar, nem o que fazer [...] (D7).

Deste modo, analisando os relatos trazidos pelas entrevistadas, pode-se perceber que as enfermeiras manifestam dificuldades emocionais em trabalhar com os pacientes em seu processo de morte e morrer. Além disso, muitas vezes a formação desses profissionais é voltada às ações técnicas e práticas, e mesmo tendo conhecimento sobre as necessidades reais do paciente e da família, e procurarem realizar as tarefas da melhor maneira possível, apresentam dificuldades para apoiar e confortar esse núcleo.

Assim, a enfermeira deve refletir e permitir que o paciente, em iminência de morte, mantenha seu direito à cidadania como um ser que raciocina, que tem capacidades e que percebe seu corpo. Porém, para que essas atitudes se concretizem, fazse necessário, talvez, que o enfermeiro recupere dentro de si a pessoa que é, e que em atitude de autodefesa muitas vezes é sufocada, devendo superar seus temores e assim contribuir para a plena humanização, abastecendo-se com toda carga dos mais nobres sentimentos, em especial, o amparo e o conforto, a solidariedade e a compaixão, provocando mudanças e transformando seu serviço de atendimento de enfermagem em algo especial, verdadeiro, indispensável. ${ }^{26-27}$

\section{CONSIDERAÇÕES FINAIS}

Como foi visto, uma das maiores ansiedades enfrentadas pelas enfermeiras, é lidar com a morte, pois a mesma surge, na maioria dos casos, como um fenômeno doloroso e de difícil aceitação, principalmente em se tratando de pacientes com câncer, que cercados de estigmas, experienciam essa situação de forma amarga e cruel, provocando nos enfermeiros reações conflituosas e impondo certos limites a quem luta sempre pela vida.

Estudar a morte é algo que pode ajudar a trabalhar com sua constante presença, surgindo daí a necessidade da profissional tornar-se familiarizada com a morte desde a graduação, com vistas a um preparo pessoal e profissional de forma a reduzir o estresse e a ansiedade ao se discutir e conviver diariamente com essas situações de sofrimento, proporcionando ao profissional a elaboração e o esclarecimento de suas preocupações frente ao desconhecido, para que seja capaz de manter uma relação interpessoal de ajuda, a qual éa essência do ato de cuidar, tanto com o paciente que necessita ser ajudado nesta fase de sua vida, quanto para com seus familiares.

\section{REFERÊNCIAS}

1. Silva VCE. O impacto da revelação do diagnóstico de câncer na percepção do paciente [dissertação]. Ribeirão Preto (SP): Universidade de São Paulo. Escola de Enfermagem de Ribeirão Preto; 2005.

2. Carvalho MMMJ. Introdução à psicologia. São Paulo (SP): Psy; 1994.

3. D'assumpção EA. Comportar-se fazendo bioética: para quem se interessa pela ética. Rio de Janeiro (RJ): Vozes; 1998.

4. Carpena LAB. Morte versus sentimentos: uma realidade no mundo dos acadêmicos de medicina. Rev Gaúcha Enferm. 2000 Jan; 21 (1): 100-12.

5. Kovacs MJ. Morte e desenvolvimento humano. São Paulo (SP): Casa do Psicólogo; 2000.

6. Boemer MR. A morte e o morrer. São Paulo (SP): Cortez; 1986. 
7. Spíndola T, Macedo MCS. A morte no hospital e seu significado para os profissionais. Rev Bras Enferm. 1994 Dez; 47(2):108-17.

8. Magalhães ZR, Santos GF, Caldeira WP. Morte nas instituições de saúde: uma abordagem ética. Enferm Revista. 1995 Dez; 2(4):15-19.

9. Machado WCA, Leite JL. Eros e Thanatos: a morte sob a óptica da enfermagem. São Caetano do Sul (SP): Yends; 2006.

10. Ferreira SS, Neves EP. Ser enfermeira vivenciando o cuidado ao cliente com câncer em tratamento quimioterápico. RECENF. 2003 Jan-Fev; 1(1):49-54.

11. Kestemberg CCF, Soria DAC, Paulo EFP. Situações de vida e morte - uma questão reflexiva. Rev Bras Enferm. 1992 Out-Dez; 4(45):259-65.

12. Quintana AM, Kegler P, Santos MS, Lima LD. Sentimentos e percepções da equipe de saúde frente ao paciente terminal. Paidéia. 2006 Set-Dez; 16(35):415-25.

13. Magalhães MJB, Silva A, Trombetti EFC, Barreiros PDVC, Requena OS, Lima RT. Sentimentos dos enfermeiros ao cuidar do paciente terminal. Nursing. 2007 Fev; 105(9):89-93.

14. Barros AJP, Lehfeld NAS. Fundamentos de metodologia científica - um guia para a iniciação científica. $2^{a}$ ed. São Paulo (SP): Makron Books; 2000.

15. Minayo MCS. O desafio do conhecimento: pesquisa qualitativa em saúde. $8^{a}$ ed. São Paulo (SP): Hucitec; 2004.

16. Ferreira YV. Paciente terminal: assistência de enfermagem. HU Revista. 1986Jan-Dez; 13(1/3):53-64.

17. Moreira AC, Lisboa MTL. A Morte - entre o público e o privado: Reflexões para a prática profissional de enfermagem. Rev Enferm UERJ. 2006 Set; 14(3):447-54.
18. Costa JC, Lima RAG. Luto da equipe: revelações dos profissionais de enfermagem sobre o cuidado à criança/ adolescente no processo de morte e morrer. Rev Latino-am Enfermagem. 2005 MarAbril; 13(2):151-57.

19. Silva JLL. A importância do estudo da morte para os profissionais de saúde. RECENF. 2005 Jul-Set; 3(12):363-74.

20. Bromberg MHPF. A psicoterapia em situação de perdas e luto. Campinas (SP): Livro Pleno; 2000.

21. Rezende MS, Kegler AL, Gomes D. Morte: uma certeza afligindo profissionais de enfermagem, familiares e pacientes. RECENF. 2004 Maio-Jun; 2(9):182-85.

22. Santoro DC, Oliveira CM. Considerações sobre morte súbita no contexto do cuidado. Rev Enferm Brasil. 2003 Set-Out; 2(5):309-13.

23. Haddad DRS. A morte e o processo de morrer de crianças em terapia intensiva pediátric a: vivência do enfermeiro [dissertação]. Belo Horizonte (MG): Universidade Federal de Minas Gerais; 2006.

24. Bellato R. A vivência da hospitalização pela pessoa doente [tese]. Ribeirão Preto (SP): Universidade de São Paulo. Escola de enfermagem de Ribeirão Preto; 2001.

25. Sousa EM, Almeida MFPV. A enfermagem interagindo com pais em situação de morte perinatal: uma visão fenomenológica. Rev Enferm Brasil. 2003 Set-Out; 2(5):302-08.

26. Carvalho MVB. O cuidar de enfermagem hoje: uma arte que se renova, uma ciência que se humaniza. RECENF. 2003 Nov-Dez; 1(6):435- 42.

27. Souza ML, Sartor VVB, Padilha MICS, Prado ML. O cuidado em enfermagem - uma aproximação teórica. Texto Contexto Enfermagem. 2005 Abr-Jun; 14(2):266-70. 